\title{
Infecções experimentaes na Leishmaniose visceral americana
}

\author{
pelo \\ Dr. Aristides Marques da Cunha
}

(Com 9 estampas)

No estudo da Leishmaniose visceral americana, as infeccões experimentaes constiluem por cerlo capilulo de grande imporlancia, não só por fornecerem dados valiosos para a idenlificação do parasita, como pela contribuição que pódem trazer ao conhecimenlo da pathologia da doença. Além disso, a infecção experimenlal do cão, poderia trazer esclarecimentos sobre o papel que desempenha esse animal na epidemiologia da infecção, como possivel depositario do virus, visto ser elle enconrado naluralmente infectado nas regiões em que grassa a doença.

- Tambem as experiencias de infecção de animaes sylvestres apresentam grande interesse quer pelo facto de poderem revelar a existencia entre nós de algum animal sensivel a infecção que se preslasse como animal de labora!orio, quer pelas indicacões que poderiam fornecer sobre a existencia de um possivel depositario sylvestre da infecção. Infelizmente as nossas experiencias nesse sentido foram muilo limitadas.

No esludo das infeccões experimentaes empregamos as seguintes amostras: amostra Luis Ferreira, isolada de um caso humano proveniente do Eslado de Sergipe em 4-936; amostras Florisvaldo, Pantoja isolados em 2-937, Miguelino, isolado em 5-937, Braulino, em 7-937, Benedicla e Isaias, em 9-937, de casos humanos, no municipio de Abaelé, Eslado do Pará; amostra Teves, isolada em 9-936 de um caso humano no Chaco argentino; amostra Amado, lambem isolado em 1-38 de homem infeclado em Bôa Vista, Estado de Mallo Grosso; amosIras Cão 1 isolado em 2-937, Jolim em 7-937 e Mangerona em 9-934, prorenientes de casos de leishmaniose visceral canina no municipio de Abaeté, Estado do Pará. Todas essas amostras foram isoladas pelo Dr. Evandro Chagas e scus collaboradores, com excepção da amostra .Jolim, isolada por nós de um cão naluralmente infeciado que nos foi enviado pelo I)r. Evandro Chagas.

Os animaes com que experimenlamos foram o cão, o macaco rhe-

* Recebido para publicaçâo a 23 de Agosto de 1938 e dado á publicidade em Dezembro de 1938. Alguns dados contidos neste trabalho foram introduzidos durante a revisão. 
sus (Macaca mulatta), o hamster europeu (Cricetus cricelus) e o camondongo branco. Dos animaes sylvestres, nossas tentativas se limitaram á cotia (Dasyprocta agouli) e ao ralo sauiá (Proechymis oris). O malerial empregado para as inoculações éra quasi sempre constituido por culturas e só algumas vezes utilisamos trilurados de baço e de figado de animaes infectados.

As culturas empregadas provinhain de tubos com meio de Nöller, N. N.N., ou meio de. Noguchi para Leplospira, sendo porém que na maior parte dos casos, lançamos mão para innculação de suspensões em agua physiologica de Leishmanias, cultivadas em placa segundo a technica de Mayer e Ray.

A via de inoculação foi quasi sempre a intra-periloneal e só excepcionalmente e para fins determinados, utilisamos a via sub-cutanea.

As dóses ulilisadas eram as vezes relativamente pequenas e constiluidas por um ou dois lubos de cultura, muitas vezes, porém, empregamos grandes dóses representadas por suspensões espessas de flagellados cullivados em placa.

As vezes procediamos a uma unica injecção, outras porém,. praticavamos injeccooes repelidas, de ordinario em numero de 4 a 6 e com intervallos variaveis, geralmente de 4 a 10 dias.

Infecção de hamster (Cricetus cricetus. As primeiras tentativas que fizemos para infeclar esses animaes tiveram resultados negativos. Cinco hamsters (hamsters 1 a 5 ), inoculados por via intra-peritoneal com culturas em meio de Noguchi da amostra Luiz Ferreira e reinoculados 10 dias depois com a mesma amostra, examinados repetidas vezes durante 9 mezes, não se mostraram infectados. Fsse faclo nos levou a admiltir a possibilidade de não serem esses roedores sensiveis i Leishmania em questão, tanto mais que essa hypothese éra corrohorada pela asserção de Mayer que diz conservarem as culluras a virulencia por espaço de mais de um anno. Tornavam-se pois necessarias novas experiencias que, conforme veremos adianle, vieram demonstrar serem os hamsters sensiveis á Leishmania visceral americana do mesmo modo que aos outros flagellados do mesmo genero hamsters 6, 8, 12. 13,16 e 17).

Os primeiros resultados negalivos podem, a nosso ver, serem explicados pela perda la virulencia das culluras durante o prazo de 7 mezes que medeou entre seu isolamento e a dala da inoculação. O desaccordo entre nossos resultados e os obtidos por Mayer provem, ao que pensamos, do faclo de ter esse autor úlilisado em suas experiencias, culturas provenientes de casos de Kala-Azar indiano, capazes de conserva- 
rem por mais tempo a virulencia como provo o facto de termos obtido infecção e morte de hamster com uma amostra de L. donovani (amosIra 45 de Adler isolada ha 10 mezes (hamsler 19 .

Quando ulilisamos culturas recentemente isoladas, oblivemos a inleccão de hamsters em $100 \%$ dos casos, tanto com amostras isoladas do homem como do cão. As inoculações eram feilas por via intra-periloneal empregando as vezes culturas em tubo com meio de Nöller; originaes ou de primeiras passagens e fazendo nesse caso uma unica injecção. Nos casos de culturas mais antigas, ulilisamos para inoculação suspensões em agua physiologica de Leishmanias cultivadas em placa segundo a lechnica de Mayer c Ray, praticando então 3 injecções com intervallos de 8 a 10 dias. Finalmente em um caso, ulilisamos triturado le baco e de figado de hamster infectado que inoculamos de uma só vez, lambem por via intra-peritoneal.

A sensibilidade do hamsler á infeccão pela Leishmania, apresenta rariaçoes individuaes como demonstra a seguinte experiencia.

Trez desses roedores (hamslers 9 a 11 ) foram inoculados com dóses iguaes do mesmo Iriturado de baço e de figado de hamster infectado hamsler 6). Apresentando um delles 68 dias após a inoculação tumefacção das palas, foi feita puncção de figado com resultado positivo que Ioi confirmado pela aulopsia effectuada 4 dias depois. Outro animal desse lote, morreu de doença intercurrente, 86 dias após a inoculação sendo a pesquisa de parasilos em esfregaços de baço e de figado negaliva. O terceiro hamsler dessa experiencia, foi sacrificado 6 mezes depois da inoculação sem apresenlar signal algum exlerno da doença e embora se mostrasse infeclado apresenlava menor numero de parasilos do que o primeiro animal, sacrificado 4 mezes antes.

Sobre a duração da infeccão poucas indicações podemos fornecer pois sómenle um animal hamsler 8 morreu de Leishmaniose e esse 7 mezes após a inoculação. Todos os demais foram sacrificados ou morreram de outras causas dado o pequeno gráo de inleccão observada. Quanto ao prazo durante o qual as culturas se conservaram virulentas após o isolamento, podemos adiantar que um hamster (hamster 16) inoculado com cultura isolada ha 1 mezes amostra 'Teves) se mostrou infectado, ao passo que outros (hamsters 14 e 15) inoculados nas mesmas condições com culluras de 8 mezes (amostra Florisvaldo e cão 1), não se mostraram infeclados no mesmo prazo, sem que se possa comludo excluir a hypothese de infeccão posterior, por terem os animaes morrido de doença intercurrente.

Já em vida do animal manifesla-se a infecção por symplomas externos representados por lesões cutaneas e tumefacção das patas. As 
lesões culaneas localisam-se na face ventral e consistem em perda de pello, erythrema e exsudação (Est. 1, fỉg. 6). A pelle assim lesada se torna extremamente friavel rompendo-se aos movimentos do animal no acto da conlencção. A tumefacção das patas apresenta-se ora nas 4 patas, ora sómente nas palas anteriores (Est. 1, figs. 1 e 2 ).

A autopsia desses animaes revelou como principal alteração o augmento de volume do baço. Os esfregaços de orgãos, mostram que os parasitos são particularmente abundantes no baço, figado e medulla ossea. Em córles hislologicos podemos verificar ainda a presença de numerosos parasilos na pelle e no intestino e em pequeno numero nas capsulas suprarenaes.

$\mathrm{Na}$ pelle lesada observa-se grande hypertrophia do epithelio com degeneração das cellulas das camadas superficiaes, no derma, enorme inliltração de cellulas mononucleares repletas de parasitas e intensa congestão (Esl. 2, fig. 2). Quando a pelle conserva aspecto macroscopico normal, ou ella não se mostra parasitada ou se encontram sómente alguns macrophagos com Leishmanias em redor dos folliculos pillo-sebaceos, conservando o resto da pelle aspecto normal (Est. 2, fig. 1).

No intestino, os parasitos são encontrados na mucosa, entre as glandulas de Lieberkühn, sendo que tambem na submucosa se podem observar alguns macrophagos parasilados.

Transcrevemos em seguida o protocollo das experiencias.

7-11-1937 - 5 hamsters (n.os 1 a 5 ) inoculados por via intra-peritoneal com cultura em meio de Noguchi da amostra Luiz Ferreira.

17-11-1936 - Reinoculados nas mesmas condições.

16-12-1936 - Um hamster foi sacriticado e autopsiado com resultado negativo.

31-12-1936 - Morreu um hamster que foi autopsiado com resultado negativo.

11-1-1937 - Um hamster foi sacrificado e autopsiado com exame negativo.

7- 5-1937 - Puncção de figado dos dois hamsters restantes, com resultados negativos.

12- 8-1937- Morreu um hamster no momento da puncção de figado sendo examinado com resultado negativo. O animal restante foi despresado.

27-2-1937 - 1 hamster $\left(n .^{\circ} 6\right.$ foi inoculado por via intra-peritoneal com 2 ce. de cultura primaria da amostra Florisvaldo.

20- 4-1937 - Puncção de figado, negativo.

27- 5-1937 -- Puncção de figado. - Presença de raras Leishmanias.

2-10-193 - () animal foi sacrificado. Apresentava então a pelle do ventre avermelhada, humida e com grande perda de pello. No momento da contenção, a pelle, devido aos movimentos do animal, rompeu-se em diversos pontos. Foi autopsiado com resultado positivo.

7- 5-1937 - 2 hamsters (n.os 7 e 8 ) foram inoculados por via intra-peritoneal com cultura primaria da amostra Miguelino. 
12- 81937 -. Morreu um dos hamsters durante a puncção de ligado sendo examinado corm resultado negativo.

18-10-1937 - Puncção de figado do hamster restante 8 com resullado positivo.

12-11-1937 - Foi observado tumefacção e erythema do labio inferior. A partir dessa data, o erythema foi se estendendo. acabando bor tomar toda a face ventral, sendo acompanhado por exsudacão e queda de pello.

6-12-1937-Morreu e foi autopsiado. com resultado posilivo.

2-10-1937 - 3 hamsters nos 9 a 11 foram inoculados por via intra-peritoneal com 2 cc. de triturado de baco e figado do hamsler n. 6.

10-12-1937 - O hamster n.o 9 apresentou tumefacção das patas sendo feita puncção de figado com resultado positivo.

16-12-1937-Esse hamster n.o 9) foi sacrificado e aulopsiado com resultado positivo.

28-12-1937 - Morreu o hamster n.o 10 e a autopsia deu resullado negativo.

8- 4-1938 - Foi sacrificado o ultimo hamster (n.o 11. A autopsia deu resultado positivo.

6-10-1937 - 1 hamster n.o 12 foi inoculado por via intra-peritoneal com cultura da amostra Jolim.

14-10-1937 - Reinoculado nas mesmas condições.

21-10-1937 - Reinoculado nas mesmas condições.

28-1-1938-Morreu e foi autopsado com resultado positivo.

16-10-1937 - 1 hamster (n.o 13) foi inoculado por via intra-peritoneal com cultura da amostra Isaias.

26-10-1937 - Reinoculado nas mesmas condições.

1-11-1937 - Reinoculado nas mesmas condições.

14- 2-1938 - Morreu e foi autopsiado com resultado positivo.

18-10-1937-1 hamster (n.o 14) foi inoculado por via intra-periloneal com cultura da amostra Cão 1.

28-10-1937 - Reinoculado nas mesmas condições.

5-11-1937 - Reinoculado nas mesmas condições.

14-1-1938 - Morreu e foi autopsiado com resultado negativo.

18-10-1937 - 1 hamster $\left(n .{ }^{\circ} 15\right.$ foi inoculado por via intra-peritoneal com cultura da amostra Florisvaldo.

28-10-1937 - Reinoculado nas mesmas condições.

5-11-1937 - Reinoculado nas mesmas condições.

18- 1-1938 - Morreu e foi autopsiaado com resultado negativo.

18-10-1937 - 1 hamster (n.o 16 foi inoculado por via intra-peritoneal com cultura da amostra Teves. 
28-10-1937 - Reinoculado nas mesmas condiçoes.

19- 1-1938 - Sacrificado e aulopsiado com resultado posilivo

27-12-1937 - 1 hamster n.o 17) foi inoculado por via intra-peritoneal com culutra da amostra Mangerona.

10- 3-1938 Apresenta lumefacção das palas dianteiras.

19- 3-1938 - Sacrificado e autopsiado com resultado positivo.

4-10-1937 - 2 hamsters nos 18 e 19 foram inoculados por via intra-peritoneal com L. donovani amostra 45 de Adler. Isolada em 11-1937).

25-10-1937 - Reinoculado nas mesmas condições.

1-11-1937 - Reinoculado nas mesmas condições:

5-11-1937 - Reinoculado nas mesmas condições.

12-11-1937 - Morreu 1 hamster n.० 18. Aulopsia. negativa.

9-12-1937-Morreu 1 hamster n.o 19. Autopsia, positiva.

Infecção do rhesus. Alé agora apenas conseguimos infectar um unico animal dessa especie. Culluras oblidlas pela puncção de baço do doente Teves, no Chaco argentino e trazidas pelo Dr. E. Chagas, mosIraram-se nos primeiros transplantes, conlaminadas apesar de conler grande numero de flagellados. Prevendo a impossibilidade de manter as culluras nessas condições, fizemos com ellas inoculação por via intraperiloneal em um rhesus. Esse animal examinado $\mathrm{em}$ vida por puncẹão de figado não se mostrou infeclado fazendo provêr um resultado negaiivo. Entrelanto, apresentando-se agonizante, foi sacrificado e autopsiado com resultado posilivo, permillindo ainda recuperar a amostra Teves que ainda conservamos no laboratorio.

Esfregaços de baço e de figado mostraram numerosas Leishmanias que éram parlicularmente abundantes no ullimo desses orgãos (Est 4, ligs. 1 e 2). Em córles histologicos podemos verificar que as lesões do ligado são mais intensas que as observadas no cão no mesmo orgão e são represenladas por infiltração de cellulas mononucleares que ao conlrario do que se dá nesse animal, se localisa exclusivamente nos espaços-porla. Outra particularidade que differe lambem do que se observa no cão é a ausencia de parasilos na pelle. Tambem no intestino não foi possivel encontrar Leishmanias.

Outros macacos foram inoculados com culluras Florisvaldo, Panloja e Amado, bem como triturado de figado e baço do rhesus Teves, sem que nenhum delles se mostrasse infeclado. Injeccões repelidas de grandes dóses de flagellados, á semelhança do que temos feilo com o cão, foram applicadas em dois macacos, mas esses morreram de tuberculose en periodo demasiado curlo para permittir qualquer conclusão. 
Prolocollo da experiencia:

23-9-1936 - Rhesus inoculado por via intra-peritoneal com 2 lubos de cultura da amostra Teves 2 a passagem contaminada.

19-3-1937 - Puncção de figado - negativa

14-6-1937 - Morreu e foi autopsiado. Esfregaços de baço, figado, medulla ossea, etc., com numerosas Leishmanias. Cultura do figado, positiva.

Infecção do cão. - A infecção experimental de cães, ao contrario do que seria de esperar, dado o facto de serem esses animaes encontrados naturalmente infectados, não é facil de obter e as primeiras lentativas que fizemos com esse fim, tiveram resultados negativos. Variando porén as condições de inoculação, oblivemos o primeiro resultado posilivo (Cão A) que foi seguido de outros com o emprego da technica que rescrevemos em seguida. Os cães que ulilisamos em nossas experiencias eran animaes novos, de cerca de 1 a 2 mezes de idade. As culturas empregadas eram sempre recentemente isoladas (cerca de 1 a 3 mezes) e provinham tanto de casos humanos como de cães naluralmente infeclados. Para as inoculacões empregamos suspensões espessas de filagellados cultivados em placas segundo a technica de Mayer e Ray. Is inoculacôes eram feitas por via intra-peritoneal e repetidas 3 a 4 vezes com inielvallos variaveis de 4 a 8 dias. Todos os animaes inoculados nessas condições e que não morreram de doenças intercurrentes durante o periodo de incubação, mostraram-se infectados tanto com culluras prorenientes de cão como do homem.

Um cão que havia sido injectado por via intra-peritoneal com suspensão espessa de Leishmanias; lambem recentemeude isoladas mas que recebeu uma unica injecção, foi observado por mais de !ım anno sem se mostrar infectado.

O prazo de incubação observado variou entre 3 á 7 mezes sendo de 3 a 4 mezes quando ulilisadas amostras de proveniencia canina e de 5 a 7 mezes nos casos em que utilisamos culturas isoladas de infeccão humana.

A . pesquisa da infecção nos animaes inoculados éra feila a primcipio pela puncção de figado, mais tarde porém, procediamos tambem ao exame da medulla ossea retirada da tibia por trepanação. Não podemos deixar de salientar as vantagens que apresenla o exame da medulla ossea para de'erminar a infecção, pois, os parasilas são muilo mais numerosos ahi do que no figado, o que facilita sobremodo o exame. E verdade que, quando pela puncção de figado, se retira um fragmento de tecido, quasi sempre se encontram parasitos, mas esses. nas phases iniciaes da doença, são tão raros que se torna preciso um exame exhaustivo 
- (las preparações para achar muilas vezes um unico parasilo, sendo em alguns casos, impossivel o sel encontro. Ao contrario, os preparados de medulla ossea, reiirada do animal na mesma occasião, mostram numero regular de parasilos, que podem assim ser encontrados com a maior facilidadle. A observação desses faclos vem mostrar que, na pesquisa de cães naluralmente infeclados a puncção de figado não constitue o melhor processo, opinião aliás já expendida por Adler. Seria pois aconselhavel, para a pesquisa de cães naturalmente infectados, o exame da medulla ossea relirada da libia por trepanação, melhodo por certo de mais facil execução que a retirada de um fragmenlo de baço aconselhado por Adler.

Com o emprego da lechnica referida acima conseguimos alé agora, infectar 9 cães. O primeiro (Cão A inoculado com amostra isolada de cão, mostrou-se infectado 4 mezes após a inoculação morrendo mez e meio depois da infeccão. Dois outros, (Cães B e C) lambem inoculados com amostra canina, apresentaram-se infeclados pela puncção de figado, 3 mezes após a inoculação. Permaneceram vivos e infectados mais de 5 mezes, morrendo de doença intercurrente não delerminada. Um oulro, (Cão D) foi inoculado com amostra humana e só 7 mezes depois, se poude verificar a presenca de parasilas no figado, vindo a morrer cerca de 2 1/2 mezes depois, de pneumonia. Os demais, apresentam infecção recente, estão vivos e em observação. Tres delles foram inoculados com culturas isoladas de 1 m dos animaes referidos (Cão B) e se mostraram infeclados 3 a $31 / 2$ mezes depois. Os (lois outros, inoculados com amostra humana (Florisvaldo) que havia solfrido 2 passagens pelo hamsler, se mostraram infectados pelo exame da medulla ossea, 5 e 7 mezes após a inoculação. Queremos assignalar que lodas as puncções de figado feilas nesses animaes, deram até agora resultados negativos.

A infecção se manifesta e.m vida do animal por febre, anemia e emmagrecimento podendo chegar ás vezes a cachexia como no cão A. Além disso observa-se lesões culaneas representadas por depilação, seborrhéa chegando mesmo á ulceração. No cão A observamos á formação de placas de keratite em ambos os olhos e no cão C, climinuição de visão attingindo quasi á cegueir completa.

Um ponto que mereceu particular altenção de nossa parte, foi a infecção da pelle. Ella é de grande imporlancia na transmissão da doença pois é dahi que provém os parasitas que no acto da picada, vão infectar os Phlebotomus, transmissores da doença. Além disso uma vez verificada a presença de cães naturalmente infeclados nas regiões em que grassa a Leishmaniose visceral americana, éra de inleresse a pesquisa do parasila na pelle desses animaes, com o 
lim de determinar si poderiam elles ou não, desempenhar o papel de deposilarios do virus.

Com excepcão do cão $A$, em que·a curla duração da infecção não permilliu um estudo systematico da infecção culanea que ficou assim limilada á verificação do parasila na pelle (Est. 6, fig. 2), em todos os demais, foram feitas biopsias de pelle de $15 \mathrm{em} 15$ dias e desse modo podemos acompanhar a marcha da infecçio culanea bem como das lesões que elle provoca.

Nos 4 primeiros cães cães A, B, C e D já bem estudados, a inleccão da pelle foi observada em lodos elles. Nos outros 4, de inlfecção mais recente, em 3 já joi possivel a verificação da presença do parasita na pelle e tudo leva a crêr que seja apenas uma questão de tempo o apparecimento de Leishmanias na pelle do restante. Essas observações mostram claramente a constancia dessa localisação parasitaria.

Un outro ponto para o qual queremos chamar a attenção é a persistencia da infecção culanea na Leishmaniose visceral do cão. Assim, geralmente, após a primeira biopsia posiliva lodos os demais mostraram a presença de parasilos na pelle e isso até a morte dos animaes.

Outro faclo ainda a considerar é a extensão da infecção da pelle pois, embora se possa observar ponlos de eleição laes como as patas em que os parasilas se installam em primeiro logar e são geralmente mais numrerosas do que em qualquer outro, cedo se extende a infecção a toda a pelle pois, Leishmanias são ahi encontradas seja qual fôr a região do corpo donde esta foi retirada.

Maior numero de parasilos e lesões mais pronunciadas foram encontradas nas patas dos cães B e C que se apresentavam com tumefacção, pariicularmente nitidas no Cão C (Est. 1, fig.'3). A presença de parasitos na pelle das palas antes de seu apparecimento em oulras regiões do corpo, foi observada nos cães $\mathrm{E}, \mathrm{F}$ e $\mathrm{G}$ nos quaes, apesar de se encontrarem parasitos relativamente numerosos na pelle das palas, nĩo foi possivel sua observação em fragmento da pelle relirada da região cervical.

E ainda interessante referir que, embora seja quasi sempre a infecção da pelle acompanhada de lesões macroscopicas, parasilos pódem ahi ser encontrados na ausencia de qualquer signal externo, conforme podemos verificar no cão $\mathrm{D}$ em que a pelle, apesar da presença de Leishmanias, conservou aspecto macroscopico normal até a morte do animal.

$\mathrm{Na}$ phase inicial da infecção da pelle, encontramos no derma macrophagos contendo alguns parasitos, geralmente 3 a 4 e que se dispóem no trajecto dos vasos. Com excepção desses macrophagos, apresenta a pelle aspecio normal. 
Mais larde o numero dos macrophagos parasilados cresce pouco a pouco e apparecem então as lesões da pelle que referiremos em seguida.

A principal alteração observada é constituida pela infiltracão do derma por cellulas mononucleares. Essa infiltração se localisa principalmente em redor dos folliculos pilo-sebaceos (Est. 5, fig. 2), sendo que as vezes se póde observar folliculos apresentando infiltração ao lado de oulros de aspecto normal, emquanto outras vezes quasi todos os folliculos apresentam inlensa infiltração. Em oulros casos a infiltração se localisa no chorion (Est. 5, fig. 1), sendo que, frequentemente, macrophagos parasilados são vistos logo abaixo do epiderma o que facilita sobremaneira sua ingestão pelos Phlebotomus no aclo da picada. EmIiim, em cerlos casos de intensa infiltração, esta se estende uniformemente a lodo o derma (Est. 6, fig. 1).

A infilltração é constituida as vezes principalmente por macrophagos parasilados e isto aconlece sobretudo quando a infiltracão não é muito intensa. Quando a infiltração se torna mais intensa, augmenta o numero de macrophagos não parasilados sendo que quando ha ulceracão, os macrophagos parasitados são muito raros ou não são enconirados de todo.

As lesões macroscopicas observadas são depillação e seborrhéa e chegam em casos extremos á ulceração.

Os qualro cães experimeñtalmente infectados que morreram ou da infecção ou de doença intercurrente, foram todos autopsiados.

$\mathrm{Na}$ autopsia, as lesões macroscopicas observadas de maneira conslanle são de pouca monta e consistem apenas em augmento de volume do baço. No cão A, encontrava-se além disso, as placas de keratite Est. 1, figs. 4 e 5), já observadas em vida do animal, o intestino fortemente congesto com conteúdo sanguinolento e os ganglios lymphalicos axillares e inguinaes augmentados de volume. Esfregaços dos orgàos mostraram parasitos muilo numerosos principalmente no baço, figado, medulla ossea e ganglios lymphaticos (Est. 7, fig. 1; Est. 9, fig. 1).

Em córles de figado podemos observar que a infiltração se localisa principalmente em redor ou ao lado da veia central do lobulo (Est. 9, fig. 2), aspecto já assignalado por Adler na infecção experimental do cão. Parasitos eram ainda encontrados nas cellulas de Kupffer e macrophagos parasilados podiam ser observados nos espaços-porta bem como na intimidade do tecido do lobulo.

O intestino apresentava-se no mesmo animal intensamente parasilado. As Leishmanias se locálisavam principalmente na mucosa em cellulas de infiltração localisadas entre as glandulas de Lieberkühn Est. 8, fig. 2), sendo que alguns macrophagos parasitados podiam ser observados tambem na sub-mucosa. 
Dos oulros animaes, os cães B e C, apresentavam raras parasilos no baço, figado e medulla ossea emquanto que no cão D: as Leishmanias, raras no baço e no figado, eram em grande numero na meduila ossea (Est. 7, fig. 2).

\section{C.̃O A}

20- 5-1937 Inoculado por via intra-peritoneal com cullura em placa da amostra Cão 1.

28- 5-1937 Reinoculado.

6- 6-1937 Reinoculado.

10- 6-1937 Reinoculado.

28- 9-1937 Puncção de figado - posiliva.

9-10-1937 Biopsia da pelle - positiva.

Entre essas datas appareceram na cornea, a principio em um dos olhos e depois no outro. placas esbranquicadas (placas de keratite), que cresceram pouco a pouco até a morte do animal.

8-11-1937 Encontrado agonizante foi sacrificado e autopsiado. Na aulopsia além das placas de keratite jí observadas em vida, apresentava o intestino congesto com conteúdo sanguinolento, os ganglios lymphaticos axillares e inguinaes augmentados de volume sendo que um dos ganglios axillares mostrava hemorrhagia em $\mathrm{um}$ dos polos. Parasitas eram muito abundantes no baço, figado, medulla ossea, ganglios lymphaticos e intestino.

$$
\text { CÃO B e C }
$$

26-11-1937 3 cães foram inoculados por via intra-peritoneal com culturas em placa da amostra Jolim.

30-11-1937 Reinoculados nas mesmas condições.

8-11-1937 Reinoculados com a amostra Mangerona.

15-12-1937 Morreu um cão. Restam 2 Cães B e C).

7- 2-1938 Biopsia da pelle em ambos - negativo para Leishmanias.

4- 3-1938 Puncẹão do figado em ambos positivas para Leishmanias.

7- 3-1938 Biopsia da pelle em ambos - negativas.

22- 3-1938 Biopsia da pelle em ambos - negativas.

8- 4-1938 Biopsia da pelle em ambos - Cão B - posiliva. Cão C - negativa.

25- 4-1938 Biopsia da pelle em ambos - positiva em ambos.

24- 5-1938 Puncção do figado do cão B para cultura - positiva.

Biopsia da pelle em ambos - positivas.

10- 6-1938 Puncção do figado do cão C para cultura - positiva.

Biopsia da pelle em ambos - positivas. A pelle da pata do cão C, mostra a presença de numerosas Leishmanias.

$27-6-1938$

Biopsia da pelle do pescoço e da pata em ambas - positivas.

15- $7-1938$

26- $7-1938$

Biopsia da pelle em ambos - positivas.

facção e ulcerações das patas tendo sido tirada photographia.

4- 8-1938 Biopsia da pelle em ambos - positivas.

19- 8-1938 Biopsia da pelle em ambos - positivas. As patas do cão C apre- 
sentam aspecto quasi normal tendo desapparecido as ulcerações.

6- 9-1938 Biopsia da pelle em ambos - positivas. O cão C apresenta perturbação da visão chegando quasi a cegueira completa.

12- 9-1938 Morreu o cão $\mathrm{B}$, sendo autopsiado. Esfregaços do baço, fígado e medulla ossea - positivos.

19- 9-1938 Morreu o cão $\mathrm{C}$, sendo autopsiado. Esfregaoçs do baço, figado $\mathrm{e}$ medulla ossea - posilivos.

\section{CÃO D}

5-11-1937 5 cães foram inoculados por via intra-peritoneal com culturas em placa da amostra Braulino.

10-11-1937 Morreram 2 cães.

12-11-1937 Reinoculados os 3 cães restantes.

17-11-1937 Morreram 2 cães.

22-11-1937 Reinoculado o cão restante (Cão D).

26-11-1937 Reinoculado.

7- 2-1938

7- 3-1938

22- 3-1938

28- 3-1938

$30-5-1938$

3- 6-1938

22- 6-1938

8- 7-1938

$25-7-1938$

9- $8-1938$

22- 8-1938

Biopsia da pelle - negaliva.

Biopsia da pelle - negativa.

Biopsia da pelle e puncção do figado - negativas.

Puncção de figado - negativa.

Puncção de figado - positiva.

Biopsia da pelle - negativa.

Puncção do figado para cullura - positiva.

Biopsia da pelle do pescoço e pata - negativa.

Biopsia da pelle - posiliva. (Raros parasitos).

Biopsia da pelle - negativa.

Biopsia da pelle - negativa.

Morreu sendo autopsiado. Esfregaco, do baço e do figado, raros parasitos e da medulla ossea, numerosos parasitos. Córtes da pelle das patas mostraram raros parasitos.

$$
\text { CĨ̃O E, F } \quad \text { e } \quad \text { G }
$$

6- 6-1938 3 cães foram inoculados por via intra-peritoneal com cultura em tubo de Nöller (original e 1.a passagem) da amostra isolada do cão B.

13- 6-1938

Reinoculados (culturas em lubo $-2 a^{a}$ passagem).

20- 6-1938

Reinoculados (culturas em tubo - $3^{a}$ passagem).

24- 6-1938

29- 6-1938

Reinoculados (cultura de placa.

4- 7-1938

Reinoculados (cultura de placa).

8- 7-1938

Reinoculados (cultura de placa).

5- 9-1938

Reinoculados (cultura de placa).

Puncção do figado: Cão $\mathrm{E}$ - positiva. Cão $\mathrm{F}$ - negativa. Cão $\mathrm{G}$ - negativa.

Biopsia de pelle: Cão E - negativa. Cão F - negativa. Cão G - negativa.

20- 9-1938 Puncção do figado: Cão $\mathrm{E}$ - negativa, Cão $\mathrm{F}$ - negativa. Cão G - positiva.

Medulla ossea: Cão $\mathrm{E}$ - positiva. Cão $\mathrm{F}$ - positiva. Cão G positiva. 
Biopsia da pelle do pescoço: Cão $\mathrm{E}$ - negativa. Cão F - negativa. Cão G - negativa.

5-10-1938 Puncção do figado para cultura: Cão $E$ - contaminada. Cão F positiva. Cão $\mathrm{G}$ - positiva.

Biopsia da pelle da pata: Cão $\mathrm{E}$ - positiva. Cão $\mathrm{F}$ - negativa. Cão G - positiva.

Biopsia dá pelle do pescoço: Cão $\mathrm{E}$ - negativa. Cão F - negativa. Cão G - negativa.

20-10-1938 Puncção do figado: Cão $\mathrm{E}$ - positiva. Cão $\mathrm{F}$ - positiva. Cão G - positiva.

Biopsia da pelle do pescoço: Cão $E$ - negativa. Cão $F$... negativa. Cão $\mathrm{G}$ - negativa.

Biopsia da pelle da pata anterior: Cão E - positiva. Cão F negativa. Cão $\mathrm{G}$ - positiva.

8-11-1938 Biopsia da pelle do pescoço: Cão E - positiva. Cão F - negativa Cão G - negativa.

Biopsia da pelle da pata anterior: Cão E - positiva. Cão F - positiva. Cão G - positiva.

$$
\text { CÃO H }
$$

2- 5-1938 2 cães inoculados por via intra-peritoneal com cultura de 1.a passagem da amostra Florisvaldo com 2 passagens pelo hamster.

9- 5-1938 Reinoculados com culturas de 2.a e 3.a passagens. (tubos).

16- 5-1938 Reinoculados com culturas de 4.a passagem. (tubos).

30- 5-1938 Reinoculados com culturas de 6.a passagem. (tubos).

4- 6-1938 Reinoculados com culturas de placa.

9- 6-1938 Reinoculados com culturas de $7^{\text {a }}$ passagem. (tubos).

13- 6-1938 Reinoculados com culturas de placa.

17- 6-1938 Reinoculados com culturas de placa.

15- 8-1938 Puncção de figado: Cão H - negativa. Cão I - negativa.

Biopsia da pelle: Cão H - negativa. Cão I - negativa.

31- 8-1938 Puncção de figado: Cão H - negativa. Cão I - negativa.

Biopsia da pelle do pescoço: Cão II - negativa. Cão I - negativa.

13- 9-1938 Puncção de figado: Cão H - negaliva. Cão I - - negativa.

Medulla ossea: Cão H - negativa. Cão I - negativa.

Biopsia da pelle do pescoço: Cão H - negativa. Cão I - negativa.

28- 9-1938 Puncção de figado: Cão H - negativa. Cão I - negativa.

Medulla ossea: Cão H - positiva. Cão I - negativa.

Biopsia da pelle do pescoço: Cão H - negativa. Cão I - negativa.

13-10-1938 Puncção do figado: Cão H - negativa. Cão I negativa.

Medulla ossea: Cão H - positiva. Cão I - negativa.

Biopsia da pelle do pescoço: Cão H - negativa. Cão I - negativa. Biopsia da pelle da pata do cão $\mathrm{H}$ - negativa.

27-10-1938 Puncção do figado: Cão H - negativa. Cão I - negativa.

Medulla ossea: Cão H positiva. Cão I - negativa.

Biopsia da pelle do pescoço: Cão H - negativa. Cão I -- negativa.

Biopsia da pelle da pata do cão H - negativa. 
14-11-1938 Medulla ossea: Cão II positiva. Cão I - negativa.

Biosia da pelle do jescocos: Cão H - negativa. Cĩo I - negativa. Biosia da pelle da pata: Cás $H$ negativa.

5-12-1938 Nedulla ossea: - Cão I - positiva.

Experiencias com camondongos. Torlas as tentativas que fizemos para infeclar esses animaes tiveram resultados negativos. Pondo de lado as primeiras inoculações feilas com a amostra Luiz Ferreira, isolada já ha algum tempo e que se mostrou incapaz de infectar o hamster, fizcmos ultimamente inoculacões com amostra humana e recentemente isolada, que havia soffrido duas passagens successivas pelo hamsler. Os camondongos foram inoculados $(;$ vezes $\operatorname{com} 0,5$ cc. de cada vez de uma suspensão espessa de Leishmanias cullivadas em placa o que conlilue uma dóse enorme para um animal tão pequeno levando em conta que, para a inoculação de cães, empregamos 2 cc. de uma suspensão semelhanle. Esses animaes examinados durante mais de 5 mezes não se mostraram infeclados o que indica ser esse roedor pelo menos. muito potico sensivel ao flagellado em questão.

Animaes sylvestres. - Nossas experiencias com esses animaes são muito limiladas a se resumem a colia Dasyprocla ajuli e ao ra!o sauiá (Proechimys oris). As experiencias com esse ullimo roedor apresentam particular interesse por ser elle muilo abundante no municipio de Abaelé, onde grassa a Leishmaniose visceral americana e poder assin ser suspeilado de depositario de virus. Um exemplar desse roe(ior, inoculado repetidas vezes com suspensĩo de Leishmanias cullivadas em placa da amostra Braulino, as mesmas suspensões com que foi inoculado no cão D e que infectaram o animal) e que recebeu ainda uma inoculação de triturado de baço e figado de um hamster infectado, examinado durante mais de 6 mezes por puncções de figado, repetidas, (' emfim sacrificado e examinado não se mostrou infeclado. Esse resullado si não exclue de lodo a hypothese de ser esse roedor depositario la doenca. torna muito pouco provavel essa hypothese.

\section{RESUMO E CONCLUSÕES}

Passando em revista as experiencias de infeccão que effecluamos e que acabamos de relalar, vemos que, as culluras isoladas de casos de Leishmaniose visceral americana quer do homem quer do cĩo, são capazes de infeclar hamsters, rhesus e cães de maneira identica ao que aconlece com as outras formas de Kala-.lzar. Notamos ainda que a evolução da doença e as lesões observadas nos animaes assim inieclados, se assemelham ao que tem sido observado nessa entermidade approximando-a de maneira singular do Kala-Azar mediterraneo. 
E sobretudo no cão que a semelhança se lorna mais patente. I infecção da pelle e as lesões por ella provocadas que observamos, não differem em nada das que tem sido descriplas na infecç̃̃o nalural do cão e já assignaladas tambem na infeccão experimental desse animal. embora de maneira menos completa do que fazemos agora aqui.

As lesões oculares com formação de placas de keratile, a infecção massiça do intestino nos casos falaes de infecção e alé mesmo as lesões do figado descriptas por Adler como peculiares á infecção experimenlal, (infiltração em torno da veia central do lobulo) constituem outros tantos caracteres que mostram a completa analogia entre as infecções do cão que obtivemos e as já observadas no Kala-Azar mediierraneo.

Além disso, a presença de Leishmanias na pelle, as vezes em grande numero e a constancia dessa localisação parasitaria, vem mostrar que o cão apresenta as condições necessarias para desempenhar o papel de deposilario de virus tal como acontece no Kala-Azar mediterraneo, tanto mais que é elle encontrado naturalmente infectado, nas regióes em que grassa a doença.

Mas não é só a infecção do cão que mostra essa semelhança; nos outros animaes tambem se verifica o mesmo facto e até pequenos signaes, laes como a tumefacção das palas assignalada nos hamsters infectados com Leishmania infantum, foram lambem observados aqui.

Por outro lado, a reacção de sôro-agglulinação, conforme mostramos em trabalho anterior, não permitte a separação das especies do genero Leishmania, pois todas ellas, quando recentemente isoladas, possuem idenlica constituição antigenica, que se modifica depois, pela conservação longo tempo em cultura. É esse facto, que deu logar ás conclusões contradiclorias a que chegaram os aulores que se occuparam do assumplo bem como aos primeiros resultados que obtivemos.

Deanle de todos esses factos, nos julgamos autorizados a concluir como já fizemos anteriormente, que o agente da Leishmaniose visceral americana é identico á Leishmania infantum.

Ao terminar, queremos deixar consignados nossos agradecimentos ao Dr. E. Chagas, por ter posto a nossa disposição as culturas de Leishmania por elle isoladas, tornando possivel deste modo, a execucão do presente trabalho. 
Experimental infections in american visceral leishmaniasis.

With cultures isolated from cases of american visceral leishmaniasis we succeeded in oblaining experimental infections in hamslers Cricelus cricetus), rhesus monkeys (Macaca mullata) and dogs.

Hamslers were infected with strains oblained from man and dogs, the intraperiloneal way having been always employed. When cultures recently isolated are used, infection is oblained practically in $100 \%$ of the animals inoculated. The first negalive results obtained by us may be explained by the use of cultures isolated some lime before aboul 7 months and which had lost already their virulence. In some cases external lesions are observed represented by allerations of the skin and swelling of the paws. The skin lesions are observed on the rentral surface and consist in depilation, erylhema and exudation. The skin thus affecled shows to be extremely friable, rupluring at the movements of the animal when hold.

On post-mortem examination, besides the lesions pointed out, the animals present enlargement of the spleen. The parasites are very numerous in the spleen, liver, bone marrow, elc. The changed skin shows considerable hypertrophy of the epithelium with degeneration of the cells of the superficial layers, inlensive infiltration of the derm by mononucleate cells full of parasiles, and strong hyperemia.

In rhesus monkey, we oblained until now, only one case of in-. fection. The inoculation was made by the intraperiloneal way with cullures in Noeller's medium, isolated from a human case of visceral leishmaniasis, found in Chaco Argentino. About 8 months after the inoculation, the monkey was found in agony and was sacrified; the post-mortem examination showed that it was intensely infected.

For infecling dogs, we employed young animals, 1 to 2 months old. The cultures were recently isolated ( 1 to 3 months) from man or (log. For the inoculation we used thick suspensions of flagellates from plate cultures by Mayer and Ray's method. The inoculations were carried out through the intraperitoneal way and renewed 3 to 4 limes wilh intervals from 4 to 8 days.

We observed an incubation period of 3 to 4 months when we used cultures obtained from dogs, and a period of 5 to 7 months, when employed human strains.

Formerly, in order to verify the infection it, was used the liver puncture; later on we also examined the bone marrow removed by trepanation. We wish to emphasize the advantages derived from the 
examination of the bone marrow, as there the parasites are much more numerous than in the liver, thus making the examination easier.

The infeclion shows itself in the animal by fever, anemia and emaciation at limes attaining cachexia. Apart from this, skin lesions are observed represented by depilation, seborrhea, and even ulceration. In the $\operatorname{dog} A$. we observed keratitis on both eyes, and in the $\operatorname{dog} C$, diminution of vision nearly atlaining complete blindness.

What called our particular attention, was the infection of the skin. In this, parasites are always found in any region of the body, although presenting some elective sites such as the paws where the parasites lirst appear and where they generally are more numerous.

At the beginning of the skin infection we see in the derm macrophages, containing parasites, generally 3 to 1 , and arranged along the rascular tracts. With the exception of these macrophages, the skin looks normal. The number of parasited macrophages increases gradually and then appear the changes of the skin here described. The main change observed is represented by infiltration of the derm by mononucleate cells. Such infiltration is mainly located around the pilo-sebaceous follicles. In other cases, the infiltration is located in the chorion. Finally, in certain cases of intense infiltration, it extends uniformly over the whole derm.

The infiltration is sometimes constituted chiefly by parasited macrophages and this occurs mainly when the infiltration is not very intensive. When the infiltration becomes more intensive, the number of not parasited macrophages increases, and in cases of ulceration the parasited macrophages become very rare or entirely disappear.

The four dogs experimentally infected which died either from the infection or from an intercurrent disease were all examined postmortem.

On the post-moriem examination, the macroscopical changes observed in a constant manner are not important and only consist in an enlargement of the spleen. In the $\operatorname{dog} \mathrm{A}$, we found keratitis already olsserved in the same living animal, and the intestine intensely congested with sanguinolent contents and the axillary and inguinal lymphatic glands enlarged and congested. Smears from the organs showed very numerous parasites, chiefly in the spleen, liver, bone marrow and lymphatic glands.

In liver seclions we observed the infiltration mainly located around or near by the intralobar vein a feature which already has been pointed out by Adler in the experimental infection of dog. Parasites were 
also found in Kupffer's cells, and a few parasited macrophages were observed in the porta-spaces as well as in the tissue of the lobule.

The intestine of the same animal was intensely parasited, the Leishmaniae being located mainly in the mucous membrane, in infiltration cells located amongst Lieberkuehn's glands and some parasiled macrophages could also be observed in the sub-mucosa.

Mice as well as the rodents Dasyprocta agouti and Proechymis oris when inoculated, did not become infected.

From the exposed we may conclude that the experimental infections oblained, present a complete analogy with those described in the Mediterrean Kala-azar.

On the other hand, the sero-agglutination test, as shown by us in a previous paper, allows no distinction of the species of Leishmania, as all the strains when recently isolated, have the same antigenic constitution which later on undergoes modifications when the Leishmaniae are preserved in culture for a long time.

Thus, we feel authorized to conclude that the agent of the visceral american leishmaniasis is identical with $L$. infantum.

\section{Estampa 1}

Fig. 1 - Hamster n.o 17 - Tumefacção das patas.

Fig. 2-Hamster n.o 17 - Tumefacção das patas.

Fig. 3-Cão C - Tumefacção das patas (em 27-7-1938).

Fig. 4-Globo ocular esquerdo do cão A (placa de keratite).

Fig. 5-Globo ocular direito do cão A (placa de keratite).

Fig. 6-Hamster n.o 8 - lesão cutanea da face ventral. 

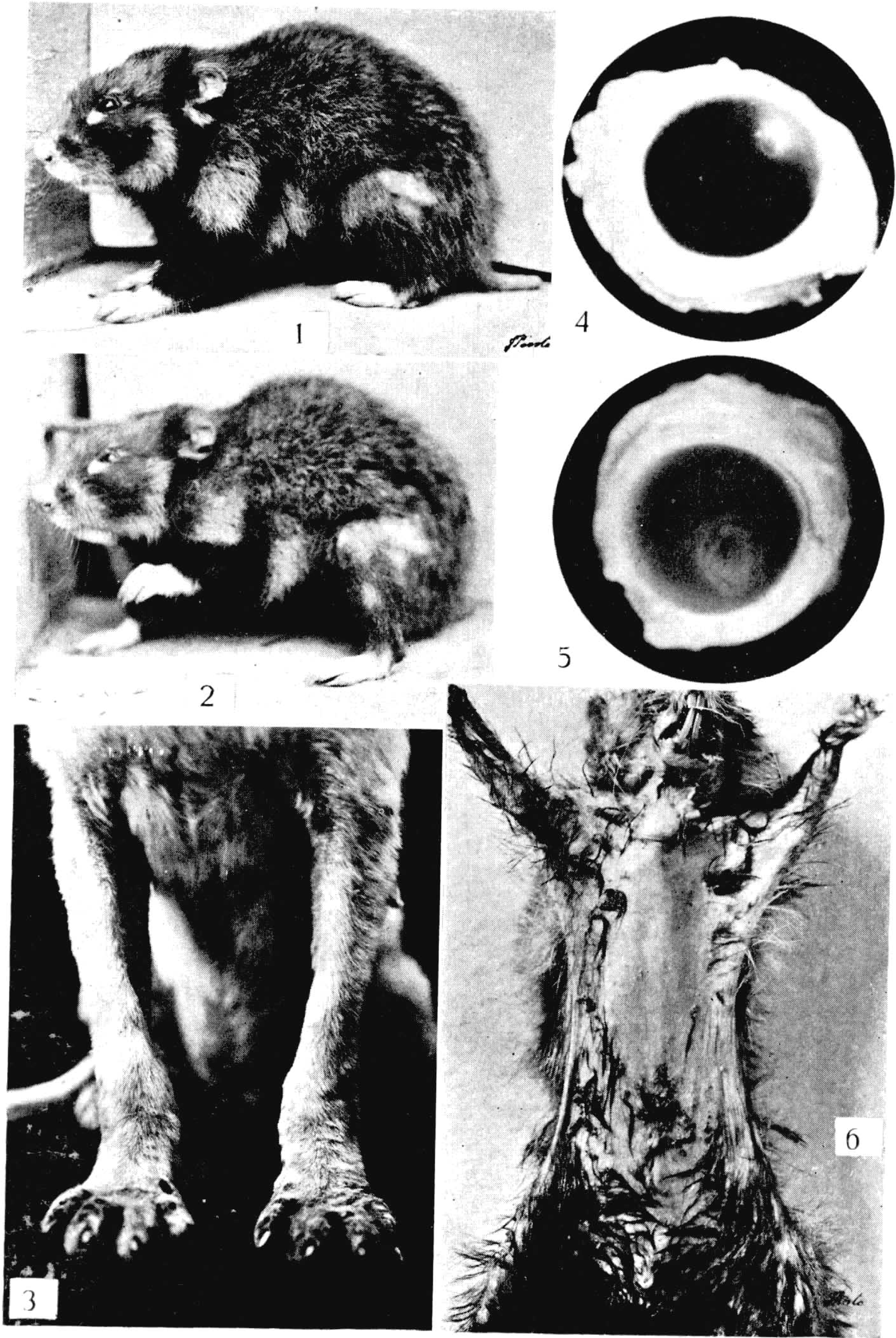


\section{Estampa 2}

Fig. 1 - Córte histologico da pelle do dorso do hamster n.o 6 . rig. 2 - Córte histologico da pelle do ventre do mesmo hamster. 


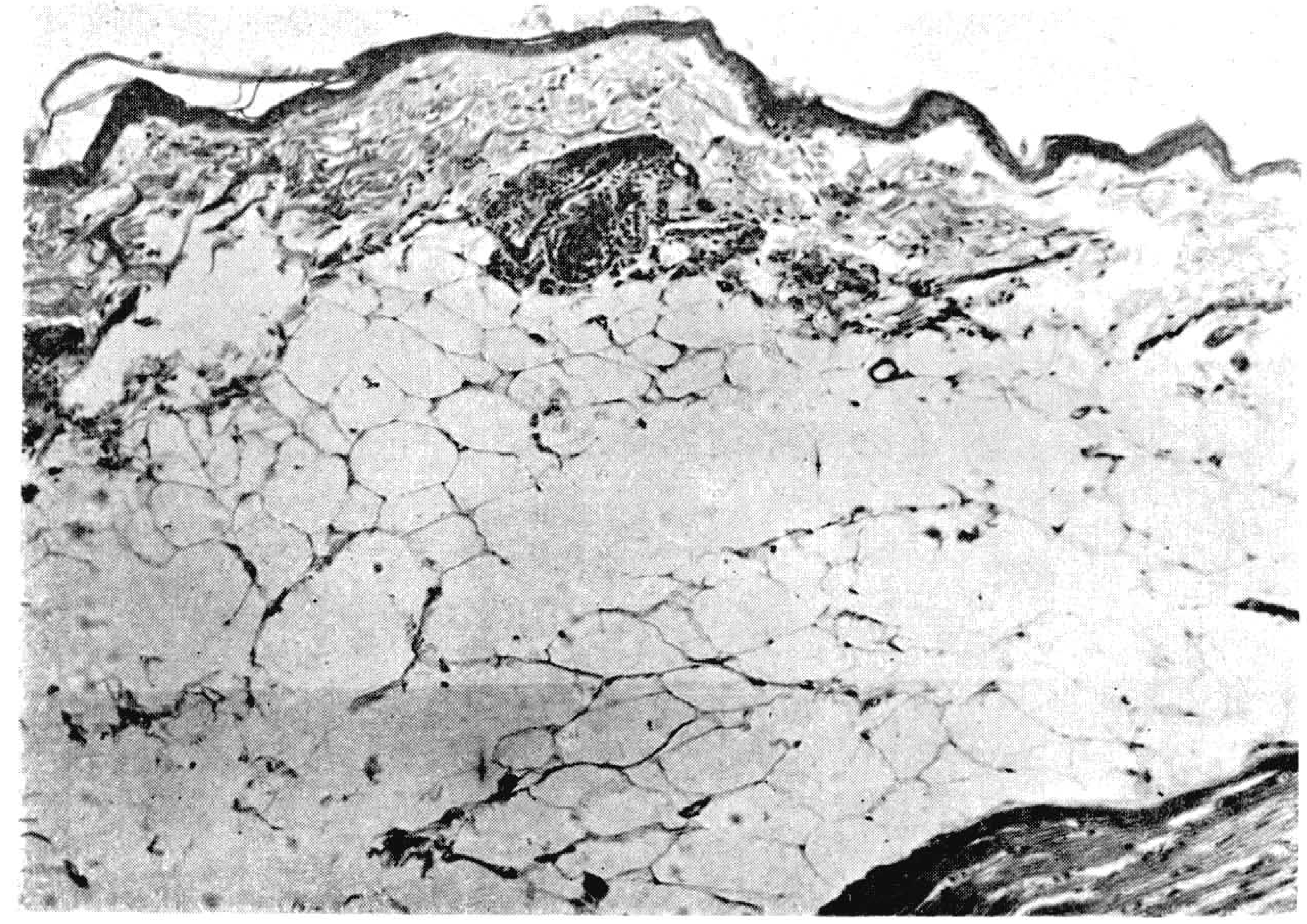

1

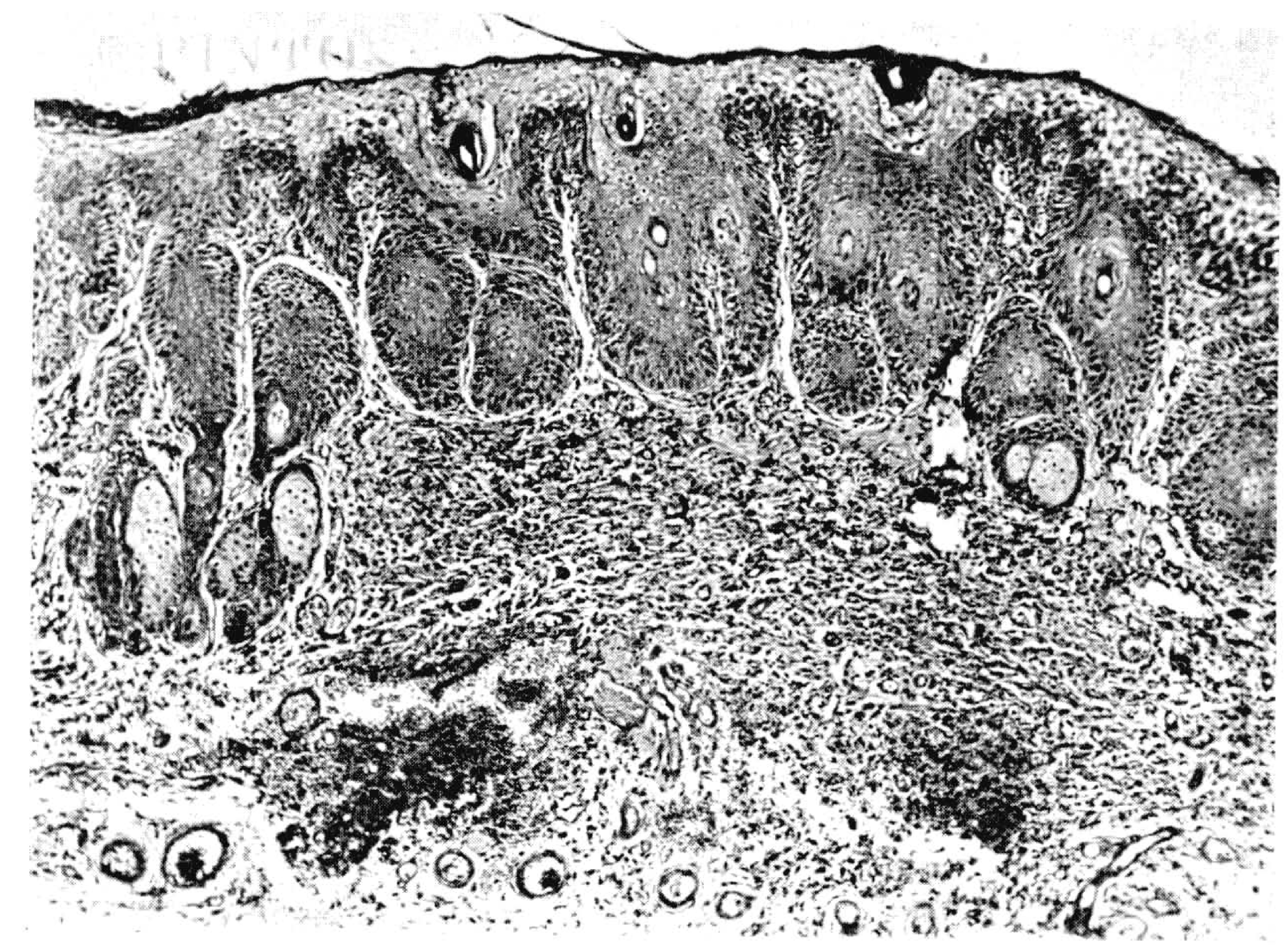

2 


\section{Estampa 3}

Fïg. 1 - Córte histologico da pelle do ventre do hamster n. ${ }^{\circ} 6$ grande augmento).

Fig. 2 - Estregaco de figado do hamster n.o 6 . 

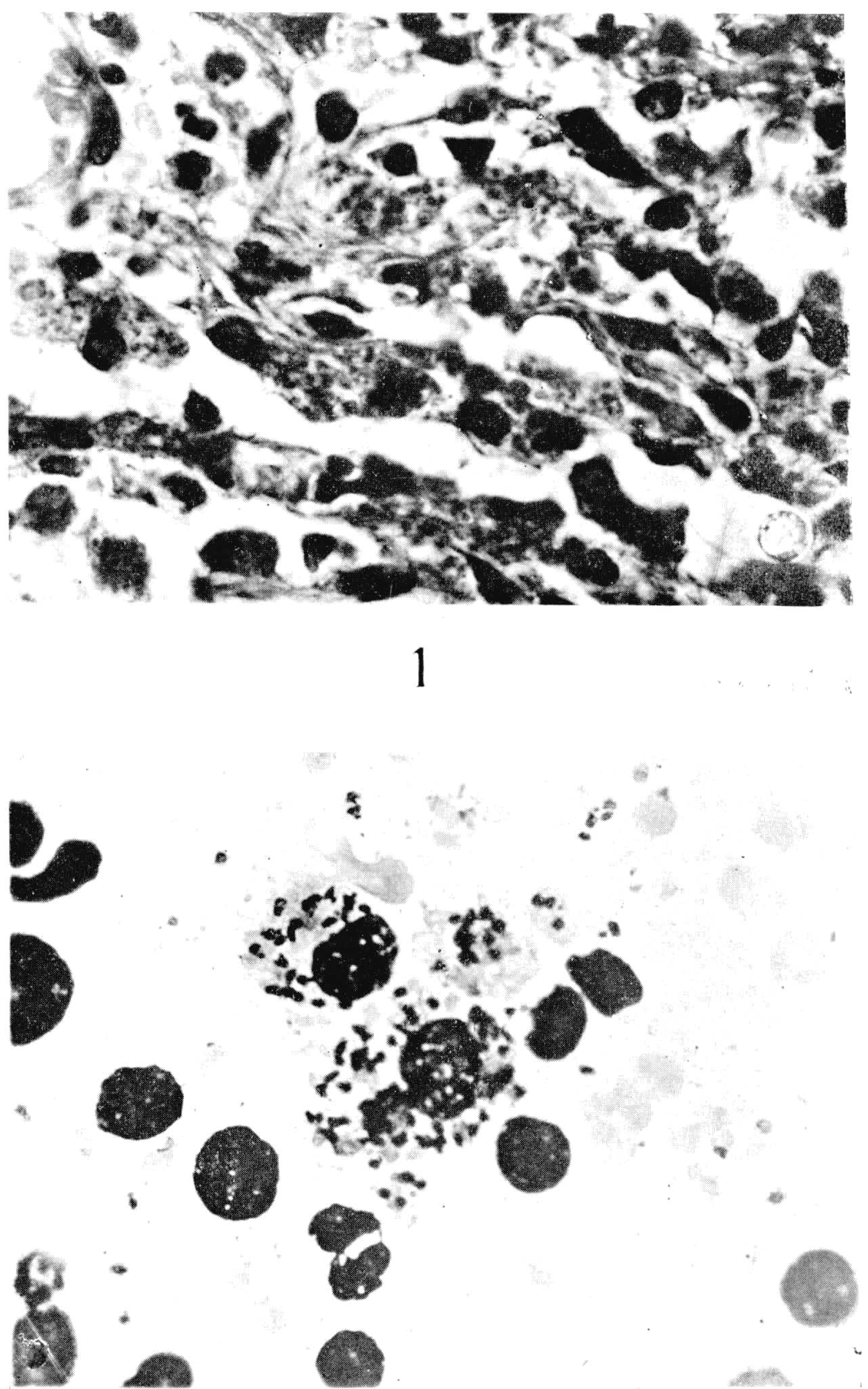

2 


\section{Estampa 4}

lïg. 1 -Lcishmanias no inlerior de um macrophago em esfregaço de figado do rhesus Teves.

Fig. 2- Macrophagos contendo leishmanias em esfregaco de baco do rhesus Teves. 

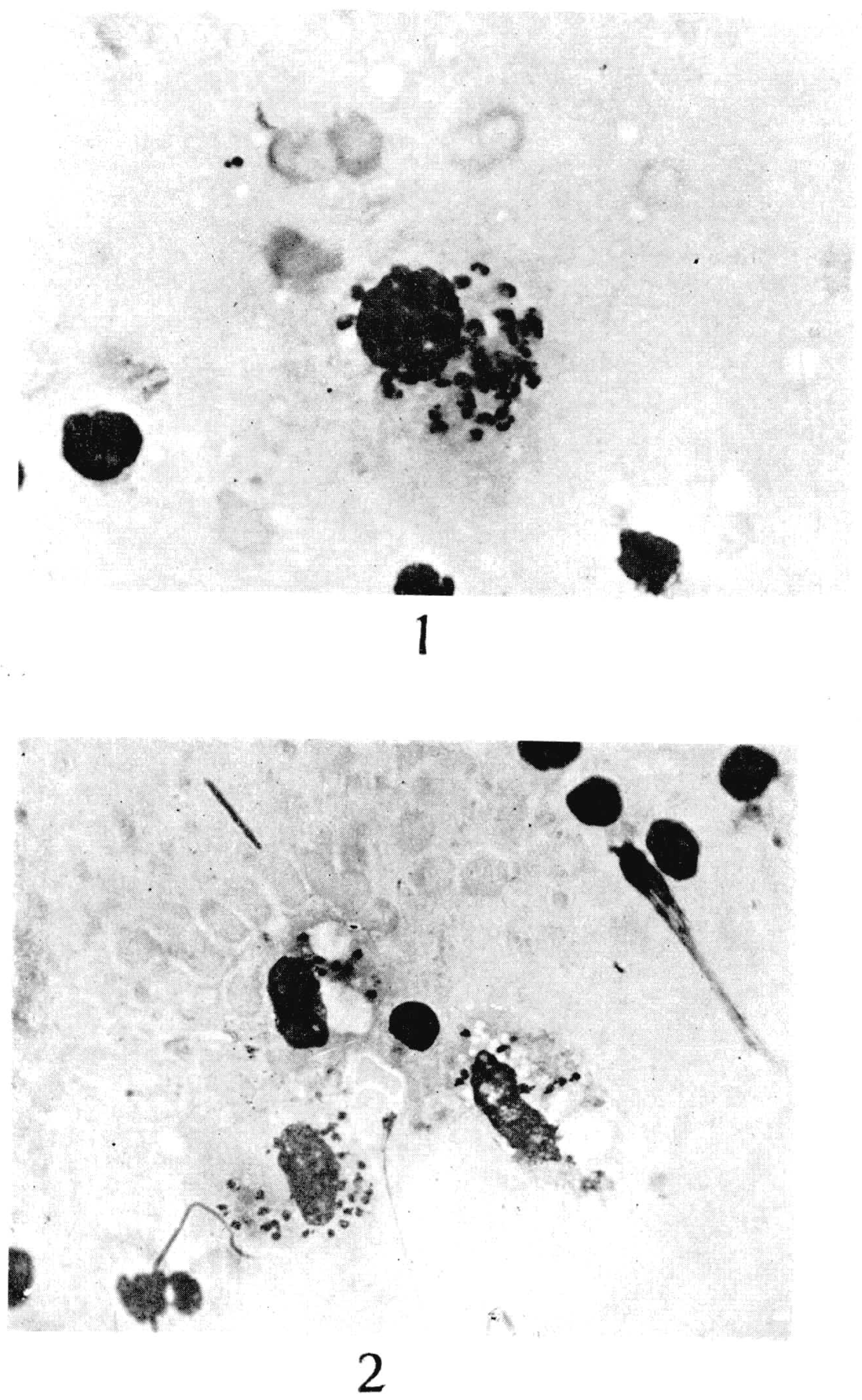

Cunha: Leishmaniose visceral americana. 


\section{Estampa 5}

Fing. 1 Córte de pelle da pala do cão C. Infillração do chorion.

rig. 2) Córte de pelle da pata do cão C. Infillraçio em redor de folliculo pillo-sebaceo. 

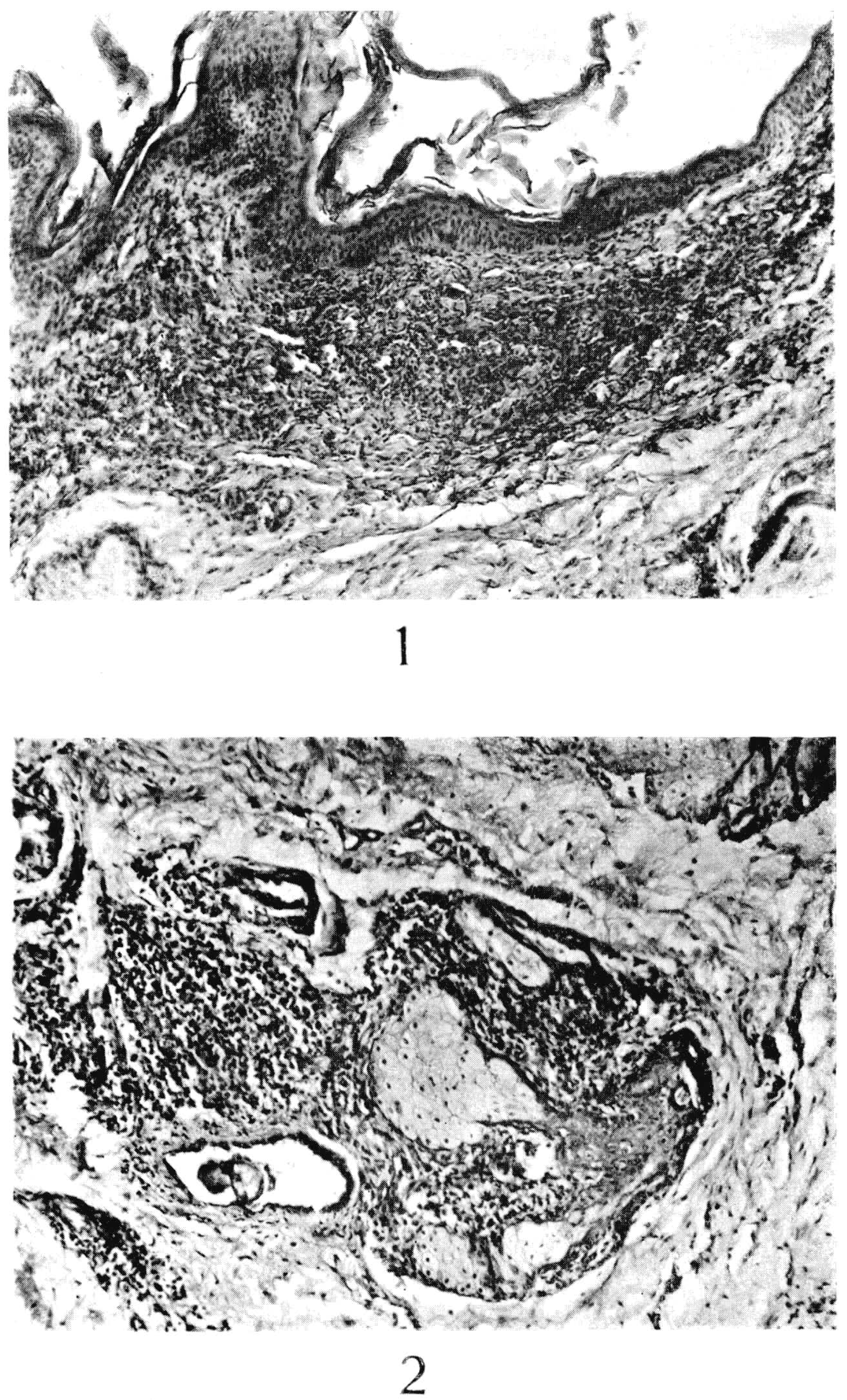


\section{Estampa 6}

Fing. 1 - Córte de pelle da pala do cão C. Infiltração uniforme do derma.

Fig. 2- Córte de pelle da região cervical do cão $A$. com grande augmento para mostrar os parasilas. 

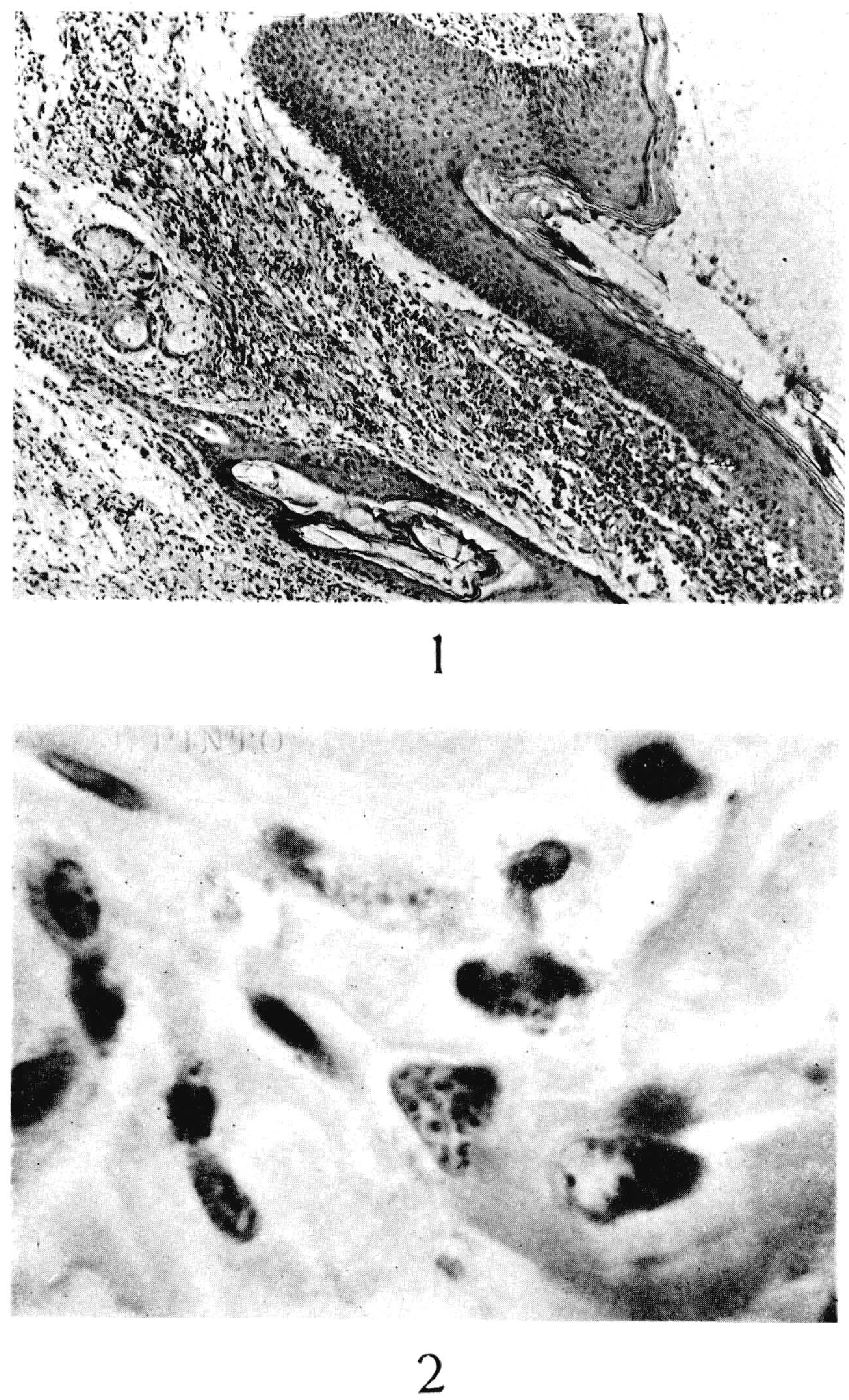


\section{Estampa 7}

lïg. 1 Leishmanias em esfregacos do baço do cão 1 .

Fig. 2 Leishmanias em esfregaco de medulla ossea do cão i). 

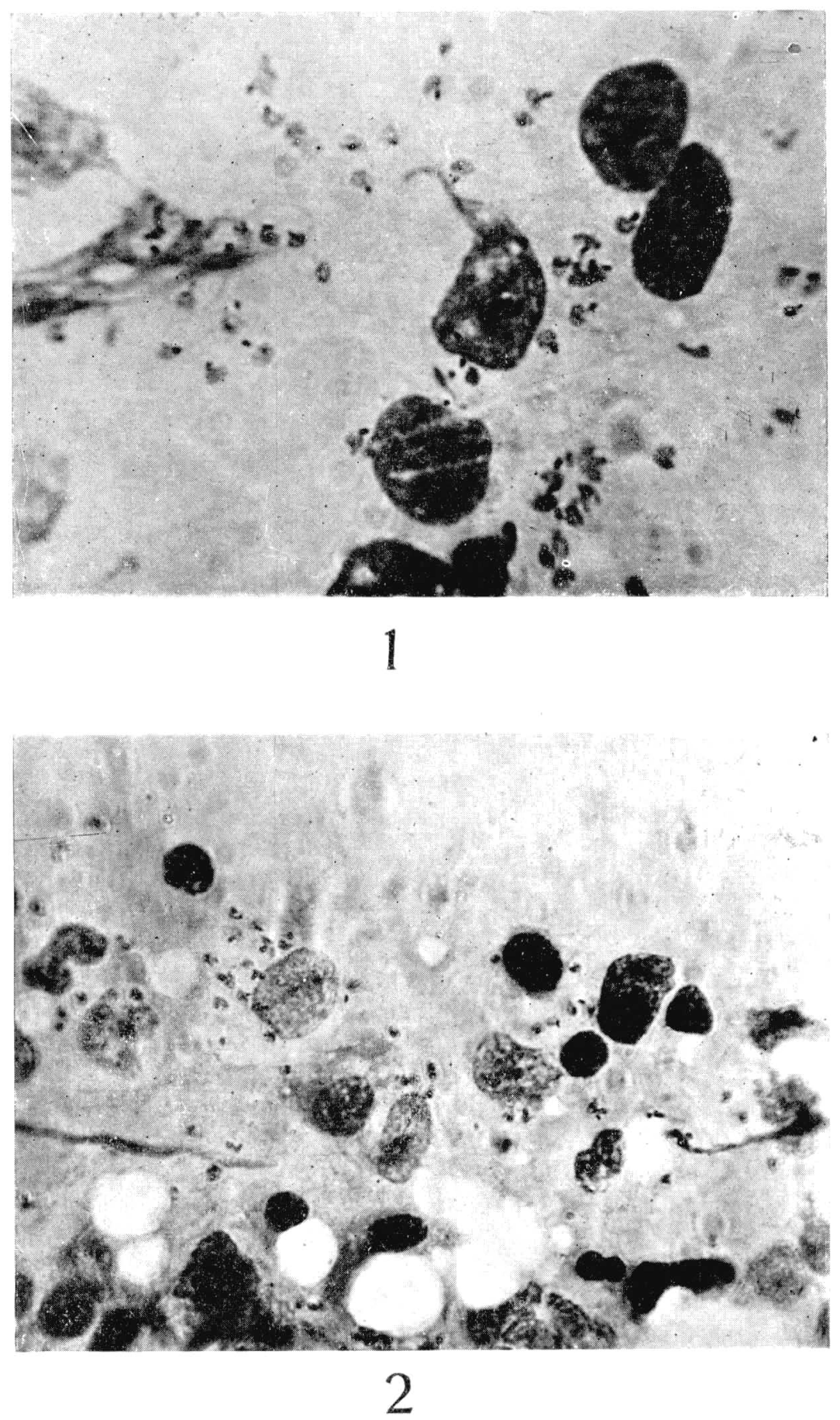

Cunha: Leishmaniose visceral americana. 


\section{Estampa 8}

Fig. 1 Córle mostrando Léshmanias na conjuncliva ocular do cĩo A Fig. 2-Córle de intestino do cão 1 mostrando lerishmanitas. 
33, 4, DEZ., 1938
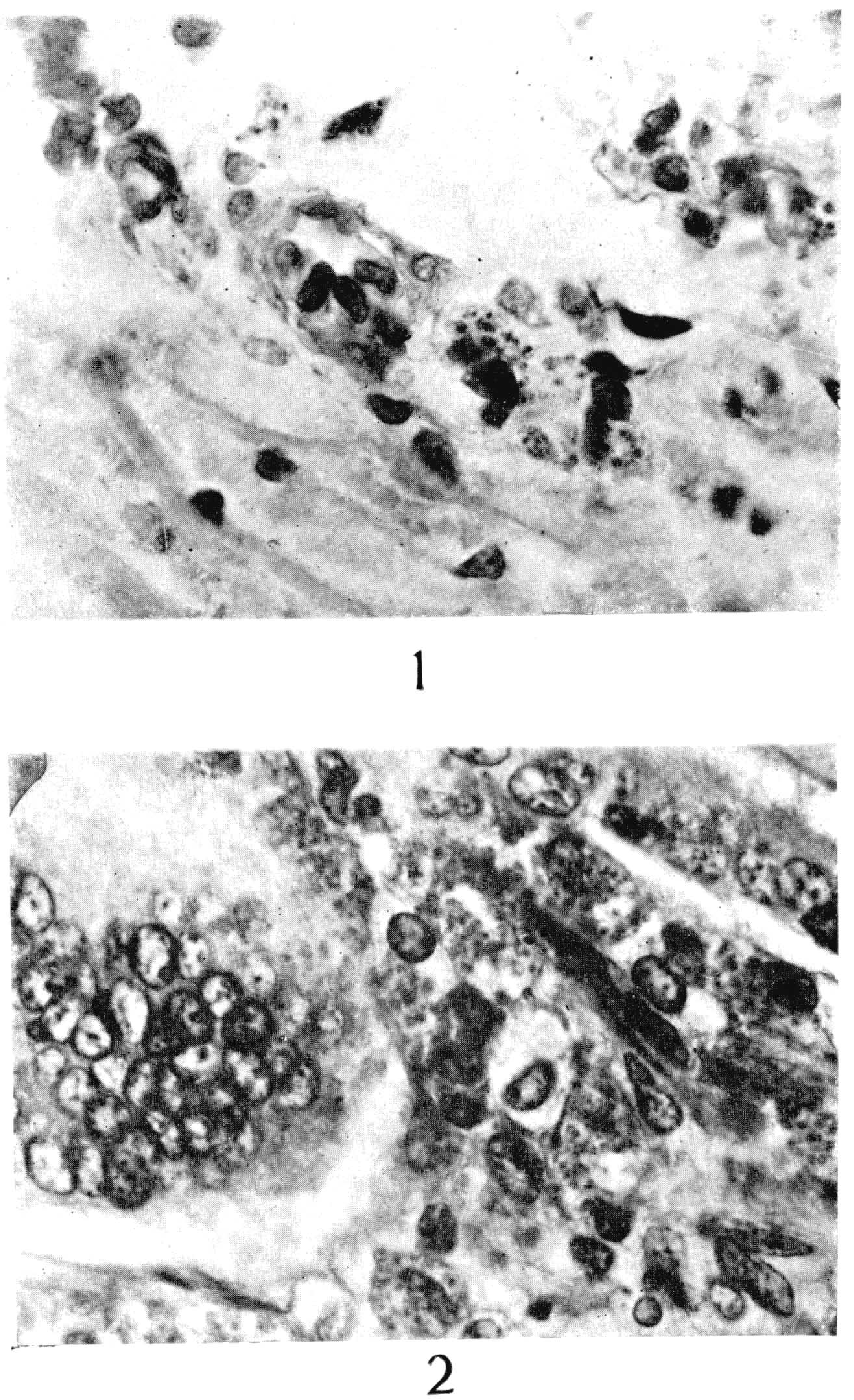

Cunha: Leishmaniose visceral americana. 


\section{Estampa 9}

Fïg. 1 Leishmanias em um ganglio lymphatico axillar do cão 1 .

Figs. 2- Córte de ligado do cão 1 mostrando a infiltracióo junto á veia central d olobulo. 

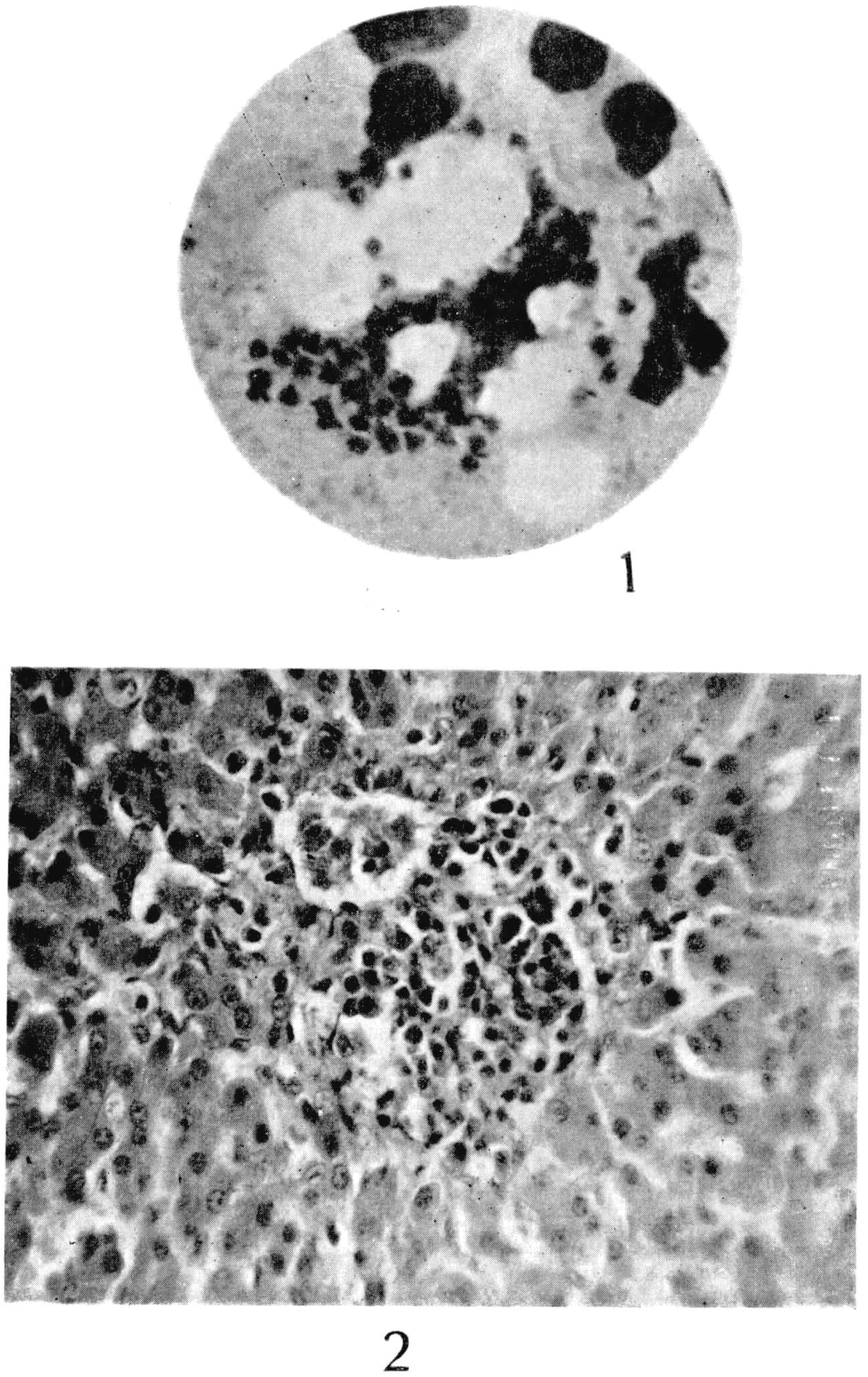

Cunha: Leishmaniose visceral americana. 